\title{
Structure, organization and a vision: Reasons for the success of wine cooperatives?
}

\author{
G.H. Schamel \\ Free University of Bozen-Bolzano, Faculty of Economics and Management, 39100 Bozen-Bolzano, Italy
}

\begin{abstract}
Several studies have found that wine cooperatives struggle to produce high quality grapes allowing them to produce better quality wines and to receive higher retail prices. In contrast, cooperatives in South Tyrol perform well and receive price premiums for wine quality relative to privately-owned local competitors. We identify the structural, organizational and social factors (i.e., elements of social capital) that may contribute to the economic success of a cooperative enterprise, surveying individual members of 13 wine cooperatives in South Tyrol. Relative payment per kg of grapes (pay-out) delivered measures the economic success of member growers. We propose that "the strength of common vision among cooperative members" is an important element identifying the "working social capital" of cooperatives and examine whether it depends on specific social and organizational variables such as commitment, trust or the strengths of personal relationships, participation in training activities and/or the presence of specific grape quality assessment criteria. Moreover, we examine if the pay-out or economic success of cooperative members can be explained by a set of structural variables and working social capital. We estimate two regression models to explain both the working social capital (i.e., strength of a common vision among cooperative members), and pay-out or economic success that cooperative members receive for delivering grapes. Results indicate that specific social factors such as member commitment, trust, personal member-winemaker relations and gender as well as organizational factors (e.g., training activities, quality assessment criteria) help to explain working social capital while physical production capital (farm size), working social capital (common vision) and indicators of human capital (involvement, vineyard consulting) are important factors to explain the economic success of cooperative members.
\end{abstract}

\section{Introduction}

Wine cooperatives often struggle to produce higher quality grapes allowing them to receive better retail prices for their wines in the market. Using an analytical model and empirical evidence, Pennerstorfer and Weiss [1] show that cooperative members have an incentive to overproduce and free ride on product quality. Frick [2] presents empirical evidence that private wineries seem to be able to produce much higher quality wines than cooperatives and publicly held wineries in Germany. Moreover, cooperative governance principles and the difficulty to monitor individual growers are among the main reasons why German wine cooperatives lag in terms of reaping rewards for established quality signals [3]. In contrast, Schamel [4] shows that wine cooperatives in South Tyrol perform well relative to their local competitors, receiving a price premium for wine quality as well as a collective reputation premium for their wines. This result is attributed to the presence of price incentives tied to grape quality, but it warrants further examination as to why these cooperatives are relatively successful and what are the contributing factors.

We motivate the paper by suggesting that a range of social factors including the strength of "working social capital" may play an important role. Many authors have stressed the importance of social capital as a specific input related to cooperative firms (e.g., [5-7]). Moreover, the literature stresses structural as well as organizational factors affect cooperative performance (e.g., $[2,8,9])$.
There is an emerging literature on cooperative success in the wine industry $([3,8,10])$. However, this literature focusses mainly on the performance of cooperatives and only a few papers relate to the contributing factors of individual member performance including social capital (e.g., [6]). Therefore, our main research objective in this paper is to identify structural, organizational and social factors that may help to explain this phenomenon. Hence, we intend to identify specific elements of social capital and organizational characteristics of cooperatives that may contribute to the economic success of individual cooperative members and in turn of cooperative wineries in South Tyrol.

The remainder of the paper is structured as follows. Section 2 provides a short literature review related to the economic and quality performance of wine cooperatives and the role of social capital in this regard. Section 3 will present the data and the empirical analysis. The main estimation results are discussed in Sect. 4 while Sect. 5 provides a summary and concludes.

\section{Brief literature review}

There is extensive theoretical and empirical work on organizational structure and performance of cooperatives in the literature. Traditional cooperatives suffer from the quantity coordination problem augmenting the total supply received from individual members not being able to control how much they will supply. For individual members, an incentive to oversupply exists to raise personal revenue. 
However, this will increase total market supply and decrease prices. Pennerstorfer and Weiss [1] use this argument to show that individual member incentives in a cooperative also lead to an interrelated quality coordination problem and to provide empirical evidence showing that wine produced by Austrian cooperatives is of lower quality relative to other firm organizations. Frick [2] gets a similar empirical result for German cooperatives which perform rather poorly in terms of product quality supplied to the market relative to owner managed firms.

Recently, this issue of resilience and performance of wine cooperatives over time has received some empirical attention. Against the standard theoretical assertion outlined above [1], Valette et al. [10] show empirically that French wine cooperatives are resilient and survive longer than incorporated wineries. They attribute this to their capacity to spread the adverse effect of any shock across members giving them additional strength relative to other ownership formats. Similarly, Declerck and Viviani [11] identify a capacity of cooperatives to absorb fluctuations at the expense of their members. Cadot and Ugaglia [12] examine the organizational strategies of Bordeaux wine cooperatives in relation to member incomes highlighting the importance of downstream strategies for cooperatives to pursue. They examine the link between leverage (being a proxy for debt) and prices paid to grape producers and show that the downstream organizational strategies chosen (including exit and vertical integration) are critically related to the lending regime. Fares and Orozco [13] describe the tournament compensation mechanism implemented by French wine cooperatives to improve their member's performance.

Nilsson et al. [5] explain the relevance of social capital for cooperatives as well as the mechanisms behind the decline of social capital in cooperatives. Social capital can be regarded as an important specific input related to cooperative [7]. We motivate this paper by suggesting that a range of related social factors including the strength of "working social capital" may play an important role for the economic success of wine cooperatives. Our definition of social capital is based on Coleman [14] and Putnam [15]. Coleman [14] postulates that "social capital, like other forms of capital, is productive and facilitates the achievement of certain ends that would be impossible in its absence". Putnam [15] identifies social capital as "social networks (among individuals) and the norms of reciprocity and trustworthiness that arise from them." Based on these definitions, we propose that "the strength of common vision among cooperative members" is an important element identifying the working social capital of cooperatives (or the network of relations among cooperative members and related norms, facilitating the achievement of economic success that would not be possible in their absence).

In Italy, wine cooperatives in the northern province of South Tyrol perform extremely well relative to their local competitors, receiving both a collective reputation and price premium for the quality of their wines [4]. Again this result is in contrast to the standard theoretical claim made before [1] and it is in contrast to the performance of wine cooperatives in the neighbouring province of Trentino a result attributed to organizational factors and the presence of price incentives tied to grape quality [4].

\section{Data and analysis}

In the present paper, we take a closer look at wine cooperatives in South Tyrol surveying member growers of all 13 wine cooperatives in the region. Our objective is to examine specific elements of social capital and structural indicators that in addition to organizational characteristics may contribute to the economic success of wine cooperatives and its member growers.

Or measure for the economic success is the payment (or pay-out) that cooperative member growers receive per $\mathrm{kg}$ of grapes delivered. Pay-out is a simple ordinal variable identifying a relative payment per $\mathrm{kg}$ of grapes, i.e., whether farmers received at least a $5 \%$ percent premium, a $5 \%$ discount or a price about equal to the average payout for all grape deliveries in the region in 2015 which was $2.23 € / \mathrm{kg}$.

Organizational factors examined are existing grapequality assessment criteria (e.g., grape acidity and visual grading), vineyard management activities (e.g., canopy management, cluster thinning), vineyard consulting offers, participation in regular training activities offered through the cooperative and active involvement in cooperative procedures (such as participation in the annual general meeting).

Structural variables examined are the farm size (in hectares of grape-growing) and the gender of the member grower. The average farm size per member surveyed is about 1.8 ha of grapes. $14 \%$ of the members surveyed are female. A summary of the descriptive statistics of all variables used in the subsequent empirical analysis is provided in Table 1.

Social factors examined include five-point Lickert scale measures for the strength of the member relationship with the winemaker, the strength of member commitment and member trust. We also measure the strength of common vision among cooperative members using a five-point Lickert scale. Based on Coleman [14] and Putnam [15], we postulate that common vision is an important element identifying the working social capital of cooperatives (or the network of relations among cooperative members and related norms, facilitating the achievement of economic success that would not be possible in their absence) and that relevant organizational and social factors may explain the strength of a common vision or the working social capital.

Specifically, we examine whether the working social capital of cooperatives as measured by the strength of common vision among cooperative members depends on specific social factors (commitment, trust, strength of the member-winemaker relation), gender, and specific organizational control variables (training activity, vineyard management activities, grape acidity and visual grading as quality assessment criteria):

$$
\begin{aligned}
\text { Common Vision }=\alpha & +\beta_{1} \text { Member Commitment } \\
& +\beta_{2} \text { Member Trust } \\
& +\beta_{3} \text { Winemaker Relation } \\
& +\gamma_{1} \text { Gender } \\
& +\delta_{1} \text { Grape Acidity } \\
& +\delta_{2} \text { VisualGrading } \\
& +\delta_{3} \text { VineyardManagement } \\
& +\delta_{4} \text { Training Activity }+\varepsilon(1)
\end{aligned}
$$


Table 1. Descriptive statistics.

\begin{tabular}{lccccl}
\hline Variable & Mean & Median & Min. & Max. & Std. Dev. \\
\hline Pay-out & 2.143 & 2 & $\mathbf{1}$ & 3 & 0.770 \\
Farm Size (ha) & 1.791 & 1.15 & 0.10 & 15 & 1.946 \\
Com1non Vision & 3.701 & 4 & $\mathbf{1}$ & 5 & 1.048 \\
Vineyard Consulting & 0.654 & $\mathbf{1}$ & 0 & $\mathbf{1}$ & 0.477 \\
Involvement & 3.307 & 4 & 0 & 4 & 1.129 \\
\hline Grape Acidity & 0.352 & 0 & 0 & $\mathbf{1}$ & 0.479 \\
Visual Grading & 0.835 & $\mathbf{1}$ & 0 & $\mathbf{1}$ & 0.372 \\
Vineyard Management & 0.648 & $\mathbf{1}$ & 0 & $\mathbf{1}$ & 0.479 \\
Training Activity & 0.839 & $\mathbf{1}$ & 0 & $\mathbf{1}$ & 0.368 \\
Winemaker Relation & 3.174 & 3 & $\mathbf{1}$ & 5 & 1.156 \\
Member Commitment & 4.530 & 5 & 1 & 5 & 0.780 \\
Member Trust & 3.801 & 4 & 1 & 5 & 1.043 \\
Gender & 0.860 & $\mathbf{1}$ & 0 & $\mathbf{1}$ & 0.348 \\
\hline
\end{tabular}

Table 2. Working social capital.

\begin{tabular}{|c|c|c|c|c|}
\hline Variable & Coef. & Std.Err. & t-stat. & Prob. \\
\hline Constant & 0.269 & 0.386 & 0.696 & 0.487 \\
\hline Member Commitment & 0.214 & 0.075 & 2.834 & 0.005 \\
\hline Member Trust & 0.113 & 0.055 & 2.054 & 0.041 \\
\hline Winemaker Relation & 0.238 & 0.052 & 4.587 & 0.000 \\
\hline Gender & 0.332 & 0.158 & 2.095 & 0.037 \\
\hline Grape Acidity & 0.240 & 0.114 & 2.099 & 0.037 \\
\hline Visual Grading & 0.398 & 0.145 & 2.737 & 0.007 \\
\hline Vineyard Management & 0.343 & 0.120 & 2.845 & 0.005 \\
\hline Training Activity & 0.434 & 0.160 & 2.710 & 0.007 \\
\hline No. of obs. & 236 & \multicolumn{2}{|c|}{ Mean dep. var. } & 3.712 \\
\hline Adj. $R^{2}$ & 0.347 & \multicolumn{2}{|c|}{ S.D. dep. var. } & 1.020 \\
\hline F-Stat. & 16.61 & \multicolumn{2}{|c|}{ D-W stat. } & 1.969 \\
\hline
\end{tabular}

Table 3. Dependent variable: PAY-OUT (Order Logit).

\begin{tabular}{cllll}
\hline Variable & Coefficient & Std. Err. & Z-Stat. & Prob. \\
\hline Farm Size & 0.362 & 0.095 & 3.801 & 0.000 \\
Common Vision & 0.356 & 0.131 & 2.725 & 0.006 \\
Vineyard Consulting & 0.566 & 0.283 & 1.996 & 0.046 \\
Involvement & 0.381 & 0.117 & 3.270 & 0.001 \\
\hline Cut 1 & 2.157 & 0.594 & 3.629 & 0.000 \\
Cut 2 & 4.205 & 0.647 & 6.502 & 0.000 \\
\hline Pseudo $R^{2}$ & 0.115 & Akaike info criterion & 1.954 \\
Schwarz criterion & 2.042 & Log likelihood & -219.7 \\
Hannan-Quinn & 1.990 & LR statistic & 57.13 \\
\hline
\end{tabular}

Moreover, we examine if the pay-out or economic success of cooperative members can be explained by the production structure, i.e., by physical capital (farm size), working social capital (common vision) and human capital (involvement, vineyard consulting).

$$
\begin{aligned}
\text { Pay }- \text { out }=\alpha & +\beta \text { Farm Size } \\
& +\gamma \text { Common Vision } \\
& +\delta \text { Vineyard Consulting } \\
& +\theta \text { Involvement }+\varepsilon
\end{aligned}
$$

Equations (1) and (2) are estimated using eviews 8 and a sample of 236 observations from a survey distributed to members of all 13 wine cooperatives operating in South Tyrol during 2016/17.

\section{Estimation results}

The estimation results for Eqs. (1) and (2) are presented in Tables 2 and 3, respectively. The results shown in
Table 2, indicate how the hypothesized working social capital in cooperatives depends on social factors, gender, and specific organizational control variables.

All social factors (member commitment, member trust and strength of the personal member-winemaker relation) are significant and positively influence the working social capital of cooperatives as measured by a strong common vision among cooperative members. In a male dominated sector, it may come as no surprise that female gender has a negative and significant impact (i.e., female is the base category for the gender dummy variable). We note that member commitment and the strength of the memberwinemaker relation are highly significant. Moreover, all specific organizational control variables included in Eq. (1) are significant and positively influence the working social capital in cooperatives. Relative to grape acidity, visual grading is the more significant quality-assessment criterion. It is a result in line with the highly significant member-winemaker relation indicator as visual grading of 
Table 4. Prediction Evalution for Ordered Logit Specification.

\begin{tabular}{lccccc}
\hline Pay-out & Obs. & Correct & Incorrect & \% Correct & \% Incorrect \\
\hline 1 & 54 & 19 & 35 & 35.19 & 64.82 \\
2 & 90 & 47 & 43 & 52.22 & 47.78 \\
3 & 87 & 46 & 41 & 52.87 & 47.13 \\
\hline Total & 231 & 112 & 119 & 48.49 & 51.52 \\
\hline
\end{tabular}

grape quality is typically administered by the winemaker upon delivery of the grapes. Vineyard management and training activity are also highly significant, reinforcing the quality orientation of wine cooperative in the region.

The results presented in Table 3 indicate that the payout or economic success of cooperative members can be explained by the physical production capital (farm size), by the hypothesized working social capital (common vision) and by indicators of human capital (involvement, vineyard consulting). Equation (2) is estimated using a ordered logit regression model since the dependent variable is measured using only three ranked pay-out categories in relation to the average pay-out for all grape deliveries in 2015 (rank 3 or at least a $5 \%$ premium above the average pay-out, rank 2 or a price about equal to the average pay-out, and rank 1 or more than a $5 \%$ discount below the average pay-out). Thus, special attention must be given when interpreting the results shown in Table 3.

First, note that due to missing observations for the dependent pay-out variable, the results for Eq. (2) are based on fewer observations $(n=231)$. In Table 3 , we observe that all variables are positive and significant. Physical production capital (measured by farm size) is highly significant and the more vineyards are a member owns, the more likely it is, that s/he will receive a higher-ranked pay-out category. Similarly, working social capital is highly significant and the more a member shares the common vision with other cooperative members, the more likely it is, that s/he will receive a higherranked pay-out category. Both indicators of human capital (involvement, vineyard consulting) are also significant. The more actively involved an individual member is in cooperative procedures (e.g., regular participation in the annual general meeting) he more likely it is, that s/he will receive a higher-ranked pay-out category.

In Table 4, we present the prediction evaluation for the ordered logit specification. It allows to infer how well the estimated model predicts the actual observations in the sample. Thus, it is a performance indicator of the result estimated using an ordered-logit specification for Eq. (2). Thus, the estimated model predicts pay-out category 1 correctly for $35 \%$ of all observations in that category and this ratio improves to $52 \%$ for pay-out category 2 and $52 \%$ for pay-out category 3 . Overall, the estimated model predicts the pay-out category for $48.5 \%$ of all observations correctly.

\section{Summary and conclusion}

Aim of this paper was to identify structural, organizational and social factors (or elements of social capital) that may contribute to the economic success of a cooperative enterprise and its members. For this purpose, we surveyed 236 individual members of the 13 wine cooperatives in South Tyrol during the spring and summer of 2017. The relative payment per $\mathrm{kg}$ of grapes (pay-out) which growers received from their cooperative in 2015 is our measure of economic success. Based on Coleman [14] and Putnam [15], we propose that "the strength of common vision among cooperative members" is an important element identifying the "working social capital" of wine cooperatives in our local context.

The economic success of wine cooperative members in South Tyrol in terms of relative payments received per $\mathrm{kg}$ of grapes may be explained by production structure, i.e., by physical capital (farm size), working social capital (common vision) and by human capital formation (involvement, vineyard consulting). With more income at stake, larger vineyard owners are much more likely to receive higher payments from their cooperative, especially if $\mathrm{s}$ /he shares a strong common vision of the cooperative with other members. Moreover, the more actively involved members are in cooperative procedures, the more likely they are to receive a higher payment for their grapes.

Our results confirm that working social capital in wine cooperatives may depend positively on specific social factors (e.g., member commitment, member trust and a strong member-winemaker relationship) as well as on organizational control variables (such as specific quality-assessment criteria or vineyard management and training activities. Further strengthening these social factors and organizational indicators may reinforce the quality orientation of wine cooperative in the region.

As far as the results are transferable to other regions, important policy recommendations may be drawn to support struggling wine cooperative. Strengthening organizational control (fair and transparent grape qualityassessment criteria and/or active engagement in vineyard management and training activities) can reinforce the quality orientation of wine cooperative. However, this must be accompanied by a set of specific social factors such as a strong member commitment, trust among members and good member-winemaker relationships to guarantee that members support organizational changes.

This study serves as a first attempt to examine factors that constitute social capital in relation to the successful organization of wine cooperatives in South Tyrol and beyond. Clearly, a similar study should also be done in other regions. Given that similar organizational structures, human capital formations as well as training and control mechanisms are in place, the nature and strength of social capital may be a crucial variable determining cooperative success elsewhere.

This research was supported by the Free University of BozenBolzano, Project No. WW2032. The author would like to thank Simon Lindemann for his contribution in conducting the survey collecting the data.

\section{References}

[1] D. Pennerstorfer, C. Weiss, Eur. Rev. Ag. Econ. 40, 143 (2013)

[2] B. Frick, Kyklos 57, 357 (2004)

[3] G. Schamel Wine Quality, Reputation and Price: How Cooperatives and Private Wineries Compete? BIO Web of Conf. 3, 03008 (2014)

[4] G. Schamel, an German wine cooperatives compete on quality? BIO Web of Conf. 5, 03003 (2015) 
[5] J. Nilsson, G.L. Svendsen, G.T. Svendsen, Agribusiness 28, 187 (2012)

[6] Q. Liang, Z. Huang, H. Lu, X. Wang, Int. Food Agribusiness Man, 18, 49 (2015)

[7] V. Valentinov, J. Coop. Stud. 37, 5 (2004)

[8] P. Fanasch, B. Frick, J. Wine. Econ. 13, 3 (2018)

[9] F.J. Santos-Arteaga, G. Schamel, J. Wine. Econ. 13, 3 (2018)

[10] J. Valette, P. Amadieu, P Sentis, J. Wine. Econ. 13, 3 (2018)
[11] F. Declerck, J.L. Viviani, Int. J. Food Sys. Dyn. 3, 106 (2012)

[12] J. Cadot, A. Ugaglia, J. Wine. Econ. 13, 3 (2018)

[13] M. Fares, L. Orozco, J. Wine. Econ. 9, 320 (2014)

[14] J.S. Coleman, Foundations of Social Theory (Belknap Press of Harvard University Press, Cambridge, Mass, 1994)

[15] R.D. Putnam, Bowling alone. The Collapse and Revival of American Community (Simon \& Schuster, New York, NY, 2000) 